\title{
ALTERNATIF MENANGANI INDIVIDU GELANDANGAN DAN BERISIKO BERSUMBERKAN AL-QURAN DAN HADIS
}

\author{
Rafiza Mohamed, Nor Faridah Mat Nong, Jaffary Awang, Ahmad \\ Sunawari Long, Zaizul Ab Rahman \\ Jabatan Usuluddin \& Falsafah Fakulti Pengajian Islam \\ Universiti Kebangsaan Malaysia \\ rafizamohamed@hotmail.com
}

Diterima 22 Juni 2017 | Direview 22 Desember 2018 |Diterbitkan 31 Desember 2018

\begin{abstract}
:
Environment, economy, social relations and lack of religious appreciation can expose individuals to problematic risks. The appreciation of religious values should be based on the Quranic and Hadith approach. The writing is aimed at examining homeless and risk groups to identify the Quran and Hadith Manbaj as an alternative to their social guidance. This writing is qualitative using content analysis techniques. Thus, manhaj 'al wisdom ' and'al din al nasibah 'are seen as one of the practical guidance to be presented. Therefore, this paper will discuss the Quranic and Hadith approaches to address the problem of homelessness and risk group by focusing on the 'al wisdom 'and 'al din al nasibah'. The application of Quranic and Hadith based is seen to be very significant in addressing individual and group issues. The outcome of the discussion suggests that alternatives suggested by Islam were recognized and significant for troubled individuals especially homeless and risk groups.
\end{abstract}

Keyword: Homeless and risk groups, the Qur'an, Hadith

\begin{abstract}
Abtrak:
Persekitaran, ekonomi, hubungan sosial dan kekurangan penghayatan agama boleh mendedabkan individu kepada risiko bermasalah. Aspek penghayatan nilai agama perlu diterapkan berasaskan pendekatan al-Quran dan Hadis. Penulisan ini bertujuan meneliti kelompok gelandangan dan kelompok yang berisiko seterusnya mengenalpasti manhaj al-Quran dan Hadis sebagai alternatif bimbingan sosial kepada mereka. Penulisan ini berbentuk kualitatif yang menggunakan teknik analisis kandungan. Justeru, manhaj 'al bikmah' dan 'al din al nasihah' dilihat sebagai salab satu bimbingan yang praktikal untuk diketengabkan. Oleh itu, penulisan ini akan membincangkan tentang pendekatan al-Quran dan Hadith bagi menangani permasalahan gelandangan
\end{abstract}




\begin{abstract}
dan berisiko dengan memfokuskan kepada kaedah 'al hikmab' dan 'al din al nasibah'. Penerapan yang berasaskan al-Quran dan Hadis dilihat sangat signifikan dalam menangani permasalahan individu serta kelompok tersebut. Hasil perbincangan menunjukkan bahawa alternatif yang dianjurkan oleh Islam ternyata diiktiraf dan signifikan dengan individu yang bermasalah terutamanya gelandangan dan individu berisiko.
\end{abstract}

Kata kunci: Bergelandangan, individu berisiko, al-Quran dan Hadith.

\title{
Pendahuluan
}

Malaysia sebuah negara yang mempunyai kepelbagaian etnik dan kepelbagaian kaum menyaksikan perkembangan masyarakat sejak zaman pasca merdeka Malaysia juga telah bergelar sebagai sebuah negara merdeka sejak hampir enam dekat yang lalu. Pelbagai perubahan turut dialami dari sudut ekonomi, sosial, politik, pendidikan dan teknologi serta perkembangan budaya dalam masyarakat. mum mengetahui bahawa kepesatan sesebuah negara berkait rapat dengan proses urbanisasi. Proses ini dikenali juga sebagai proses perbandaran yang bertujuan membangunkan negara. Urbanisasi dikatakan mempunyai kaitan dengan globalisasi. Globalisasi yang berlaku dalam gelombang yang ketiga ini memberi kesan bukan sahaja dalam bidang ekonomi, perdagangan, teknologi maklumat dan sosio-budaya tetapi juga dalam bidang kebudayaan, cara hidup dan kepenggunaan. Oleh itu ia dilihat memberi kesan kepada masyarakat khususnya yang berhadapan dengan kepesatan pembangunan. Belbagai masalah sosial timbul selaras dengan perkembangan kemajuan negara yang membuatkan setiap keluarga dan masyarakat lebih mementingkan kebendaan, sebaliknya penekanan terhadap nilai moral dan agama semakin berkurangan. Pernyataan ini dilihat sangat berkait rapat dengan situasi semasa kini. ${ }^{1}$

Menjelaskan bahawa Islam menggariskan fikiran manusia dan kegiatan fitrahnya ke arah suatu ketetapan melalui sistem yang wajar dilalui oleh individu atau kelompok masyarakat demi melahirkan masyarakat yang tinggi dan bertamadun. Namun asakan arus globalisasi yang berlaku telah memberikan kesan terhadap pembentukan masyarakat yang bertamadun tinggi. Pesan globalisasi telah memecahkan identiti mereka yang dari kalangan modenisme, Islamisme, tradisionalisme, sekularisme, nasionalisme atau gelandangan dan ia

\footnotetext{
${ }^{1}$ Mariani Mansor, "Faktor-Faktor Persekitaran Ekologikal Manusia Ke Atas Perkembangan Personaliti Dan Daya Tahan Kanak-Kanak Mangsa” (Universiti Kebangsaan Malaysia, 2004).
} 
dilihat semakin hari semakin meningkat. ${ }^{2}$. Namun Islam mempunyai dasar yang tersendiri dalam membentuk masyarakat untuk memastikan pembentukan masyarakat yang dinamik dalam segenap lapisan ia bergantung kepada persekitaran yang teratur dan selesa. ${ }^{3}$

Individu yang dibesarkan dalam persekitaran yang kondusif, selesa, dan penuh kasih saying dikatakan cenderung untuk memiliki perkembangan emosi dan psikologi yang baik. Kebiasaannya mereka akan membesar sebagai individu yang bertimbang rasa dan berkahlak mulia ${ }^{4}$; Ia menjamin keseimbangan personaliti dan tingkah laku yang baik bagi seseorang individu. Hal ini seterusnya akan menyumbang kepada pembentukan masyarakat yang berdaya saing, produktif, serta positif mendepani cabaran dalam kehidupan. Namun pembentukan masyarakat yang positif dan berdaya saing ini tidak terjadi dalam kalangan gelandangan berikutan keadaan mereka yang bergelandangan. Mereka dikatakan mengalami tret personaliti dan penghayatan agama yang rendah. ${ }^{5}$ Situasi ini dilihat mempunyai kaitan dengan individu berisiko yang dapat dikenal pasti menerusi ciri-cirinya berdasarkan kepada kes penglibatan salah laku dan faktor-faktor penyebab serta pendorong mereka melibatkan dirinya dalam perbuatan yang salah sehingga menyalahi had toleransi nilai dalam masyarakat. Mereka adalah golongan yang sukar menerima penyesuaian diri dan kondisi ini amat signifikan dengan gelandangan yang tidak dapat menyesuaikan diri dengan masyarakat dan arus globalisasi.

Persekitaran yang baik perlu bagi menghasilkan akhlak yang baik dan akhlak yang baik itu perlu lahir dari diri sendiri berdasarkan pengamatannya kepada faktor-faktor persekitaran yang boleh mempengaruhi tabiat hidup manusia. ${ }^{6}$ Hassan berpendapat, persekitaran mampu memberi kesan terhadap penghayatan nilai akhlak seseorang. ${ }^{7}$ Ia merupakan proses pengukuran nilai diri.

2 Nor Faridah, Identiti Muslim Menurut Pandangan Tariq Ramadhan (Kuala Lumpur: Institut Terjemahan dan Buku Malaysia Berhad., 2015).

3 Jawiah Dakir, Dasar Dan Kaedah Pembentukan Masyarakat Islam Menurut Perspektif Al-Sunnah (Selangor: International Law Book Services., 2008).

${ }^{4}$ Mariani Mansor, "Faktor-Faktor Persekitaran Ekologikal Manusia Ke Atas Perkembangan Personaliti Dan Daya Tahan Kanak-Kanak Mangsa."

${ }^{5}$ Rafiza Mohamed, Gelandangan Antara Tret Personaliti Dan Religiositi., Pertama (Kuala Lumpur: Institut Terjemahan dan Buku Malaysia Berhad., 2015).

${ }^{6}$ Ibn Khaldun, Abd al-Rahman bin Muhammad Khaldun al-Hadrami, Mukaddimah Ibn Khaldun.

Terj. Dewan Bahasa Dan Pustaka (Kuala Lumpur: Dewan Bahasa dan Pustaka, 2002).

${ }^{7}$ Hassan Langgulung, Asas-Asas Pendidikan Islam (Kuala Lumpur: Dewan Bahasa dan Pustaka, 1987). 
Pelbagai pendekatan telah direalisasikan untuk membantu kelompok gelandangan dan individu berisiko agar menjalani kehidupan yang mapan. Antara yang paling mendapat perhatian adalah perkhudmatan kaunseling. Dalam kajian yang dilakukan di Pusat Rujukan Intervensi Anjung Singgah PRIAS Kuala Lumpur, telah mendapati seorang kaunselor khas disediakan untuk gelandangan pusat terbabit. ${ }^{8}$ Pendekatan kaunseling telah digunapakai dalam menangani gelandangan dan individu berisiko. ${ }^{9}$ Namun pendekatan Islam yang berteraskan al-Quran dan hadith sepenuhnya didakwa oleh para sarjana memberikan kesan yang lebih baik dan positif. Justeru kajian ini bertujuan menerokai pandangan para sarjana dalam menyediakan alternatif menurut al-Quran dan hadith bagi membantu menangani individu dan kelompok gelandangan serta individu berisiko.

\section{Metode}

Kajian ini berbentuk kualitatif yang melibatkan kajian kepustakaan. Kaedah analisis kandungan atau teks (texture analysis) digunakan dalam kajian ini. Ia merujuk kepada penjelasan secara objektif dan sistematik terhadap maklumat-maklumat yang wujud secara tersirat. ${ }^{10}$ Kajian kepustakaan ini adalah bertujuan mendapatkan maklumat berkaitan manhaj yang sedia ada sebagai bimbungan sosial kepada kelompok gelandangan dan kelompok individu berisiko. Sebanyak lima sumber pengumpulan data yang digunakan dalam kajian ini yang merujuk kepada teori dan suasana dalam teks.

\section{Pembahasan}

Tipologi atau istilah gelandangan kini tidak asing lagi dalam masyrakat. istilah gelandangan tersebut, merujuk kepada individu yang tinggal di tempat perlindungan sementara yang disedia dan dioperasi oleh organisasi awam atau swasta, tempat perlindungan sementara atau peralihan oleh pihak awam atau swasta.

National Survey of Homeless Assistance Providers and Clients (NSHAPC) pula telah mendefinisikan golongan gelandangan secara rasmi sebagai individu

\footnotetext{
${ }^{8}$ Rafiza Mohamed, Gelandangan Antara Tret Personaliti Dan Religiositi.

9 Cohen, S., Mermelstein, R., Kamarck, T. \& Hoberman, H. M, Measuring the Functional Components of Social Support. Dlm. I. G. Sarason \& B. R. Sarason (Pnyt.). Social Support: Theory, Research and Application (Martinus Nijhoff Boston, 1985).

10 Ahmad Munawar \& Mohd Nor Shahizan, Memahami Kuantitatif \& Kualitatif Dalam Penyelidikan Pengajian Islam (Bangi: FPI Universiti Kebangsaan Malaysia., 2012).
} 
yang tinggal di sesuatu tempat perlindungan kecemasan atau program perumahan peralihan; individu yang tinggal di hotel kebajikan atau hotel baucher; individu yang tinggal di bangunan yang ditinggalkan; individu yang tinggal di tempat perniagaan, individu yang tinggal di dalam sebuah kereta atau kenderaan lain atau individu yang tinggal di luar; individu yang tinggal kekal di bawah Program Perumahan Malaysia di bawah Akta Orang-orang Papa 1977 (Akta 183) dan (dipinda 1985, 1996, 2002) yang diperuntukkan untuk menjaga dan memulihkan orang-orang papa dan mengawal kutu rayau. Akta ini mentakrifkan orang papa sebagai seseorang individu yang didapati mengemis di sesuatu tempat awam dengan sebegitu cara menyebabkan atau mungkin menyebabkan kegusaran kepada orang-orang yang lazim mengunjungi tempat itu atau pun hingga mengadakan kekacauan.

Mendapati bahawa gelandangan di Kuala Lumpur adalah terdiri daripada yang mereka yang tidak mempunyai kemampuan memiliki rumah. ${ }^{11}$ Pada pengamatan pengkaji definisi gelandangan dikeluarkan berpandukan pada konteks semasa serta keadaan dan kondisi sesebuah negara. Hal ini terjadi apabila banyak kajian berkaitan gelandangan dilakukan dengan rancak sejak dua dekat yang lalu. ${ }^{12}$ Oleh itu definisi dibuat dengan melihat fenomena gelandangan berdasarkan faktor dan punca. Definisi di Negara Asia lebih signifikan dengan masalah kemiskinan pada awal tahun 70an. Namun kini definisi yang lebih luas melibatkan faktor ekonomi, penghayatan agama yang rendah dan keruntuhan sistem sokongan emosi. ${ }^{13}$ Berdasarkan definisi ini dapat disimpulkan gelandangan dikaitkan dengan keadaan semasa sebagai punca serta sikap yang bermasalah. Para sarjana mendakwa sejarah kemunculan gelandangan di Malaysia mempunyai kaitan yang signifikan dengan budaya lepak yang hangat diperkatakan sekitar tahun 1990an. Masalah sikap ini juga mempunyai kaitan yang signifikan dengan individu yang berisiko yang terdiri daripada individu yang mempunyai masalah akhlak, identiti dan personaliti serta sering membuang masa dan terlibat dalm pelbagai kes salah laku, jenayah dan masalah sosial lain. Dalam menghuraikan manhaj al-Quran yang menjadi

\footnotetext{
11 Sharifah Mariam alHabshi, "Homelessness in Kuala Lumpur Malaysia: A Case of Agenda Denial," International Journal Of Social Science Tomorrow 1 (2012): 2.

${ }^{12}$ Wong Kin Yap, Lee Chew Chang, Mohd saiful Azri Mohd Fouzi, Muhamat Hamzah Eksan, Muhd Farid Ashman Abd Latif, Masalah Gelandangan Kuala Lumpur: Satu Tinjauan (Pengantar Dasar Sosial) (Kuala Lumpur: Universiti Malaya, 2014).

${ }^{13}$ Norazizaliza, "Tahap Tekanan Dan Kesediaan Mendapatkan Khidmat Kaunseling Golongan Gelandangan Di Rumah Anjung Singgah.”
} 
asas dan penyelesaian terhadap isu sahsiah Allah SWT. telah menyebutnya dengan jelas dalam Qs. al-Baqarah: 269.

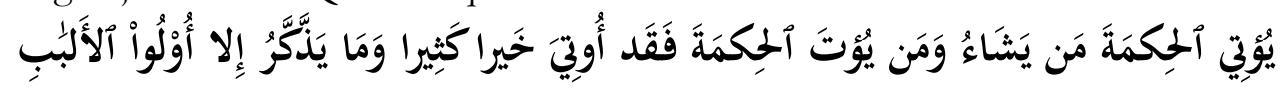
Allah menganugerabkean al bikmah (kepahaman yang dalam tentang Al Qur'an dan As Sunah) kepada siapa yang Dia kehendaki. Dan barang siapa yang dianugerabi al hikmah itu, ia benar-benar telah dianugerabi karunia yang banyak. Dan banya orang-orang yang berakallah yang dapat mengambil pelajaran (dari firman Allab).

Qs. Al-Nahl: 125

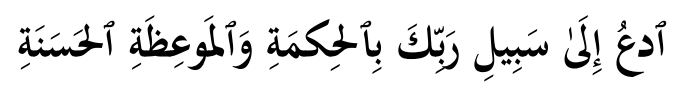

Serulah ke jalan Tuhanmu (wahai Muhammad) dengan hikmat kebijaksanaan dan nasibat pengajaran yang baik. dan berbahaslah dengan mereka (yang engkau serukan itu) dengan cara yang lebih baik.

Berpandangan bahawa apabila Allah menyebut tiga cara berbeza dengan masih wujud toleransi antara sebahagiannya dengan sebahagian yang lain membuktikan bahawa perlunya kepada metod yang berbeza dan jelas dalam hal keadaan tertentu dengan cara tertentu. ${ }^{14}$ Dalam pengamatan pengkaji al-Quran telah menyebut sebanyak 20 kali perkataan hikmah, dalam 19 ayat dan 12 surah yang membuktikan adanya metod hikmah yang perlu digunapakai dalam segenap urusan insani.

Hikmah juga mempunyai banyak pengertian, antaranyammbawa maksud adil, berpengetahuan, kenabian, al-quran dan Injil. Walau bagaimanapun hikmah adalah kesan daripada kata-kata, tindakan dan kepercayaan dengan meletakkan sesuatu pada tempatnya berdasarkan disiplin dan keyakinan. Hikmah dibahagikan kepada dua jenis iaitu hikmah yang bersifat teori 'bikmat nazariah' dan hikmah yang bersifat praktikal ' bikmat 'amaliah'. Kedua-duanya disebut secara berangkai di dalam al quran untuk memperjelaskan bahawa hikmah itu adalah metod yang diturunkan oleh Allah s.w.t sebagai panduan atau kompas bagi setiap individu dalam mengatur perilaku dan percakapan agar seiring dengan keindahan agama yang dibawa dan diamalkan. Gambaran kedua-dua entiti hikmah tersebut boleh diperhatikan dalam rajah 1.2.

\footnotetext{
${ }^{14}$ Al-Razi, Muhammad ar Razi Fakhruddin, diau al din, Tafsir Al Fakhru Al Razi. (Beirut: Dar al Fikr, 2005).
} 
Rajah 1.2 bahagian hikmah dalam al-Quran

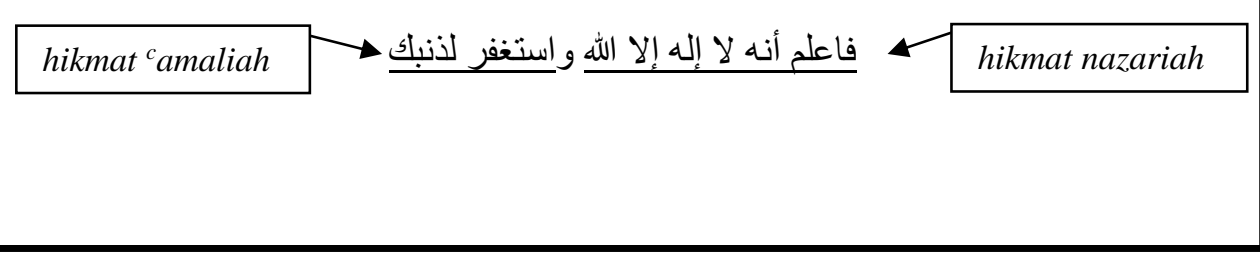

Kedua-dua jenis hikmah ini dikaiykan secara langsung dengan firman Allah s.w.t dalam Qs. Muhammad: 19 sebagai 'alaqah yang saling berkaitan.

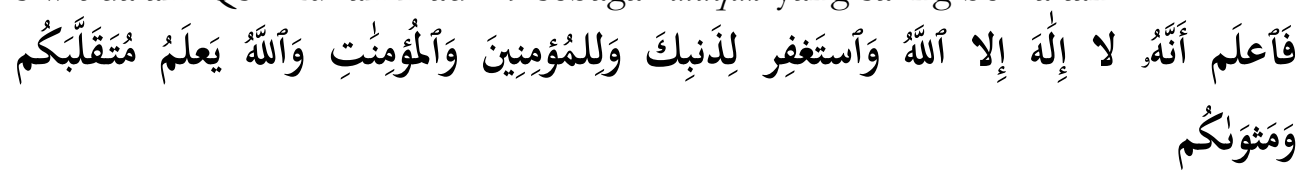

Oleh itu, maka tetapkanlah pengetahuanmu dan keyakinanmu (wahai Muhammad) bahawa sesunggubnya tiada Tuban yang berhak disembah melainkan Allah dan mintalah ampun kepadaNya bagi salah silap yang engkau lakukan dan bagi dosa-dosa orang-orang yang beriman lelaki dan perempuan dan (ingatlah), Allab mengetahui akan keadaan gerak-geri kamu (di dunia) dan keadaan penetapan kamu (di akbirat).

Menurut pada asasnya al-hikmah ditafsirkan sebgai hujah yang pasti yang membawa kepada akidah yang betul. ${ }^{15}$ Manakala menafsirkan al-hikmah sebagai al-Quran. Pendapat ini sangat hampir dengan ${ }^{16}$ yang menyatakan alhikmah ialah sebagai apa-apa yang diturunkan. Perkataan yang diturunkan itu merujuk kepada al-Quran. Hakikatnya penafsiran yang umum dan khusus tersebut membawa maksud sebagai apa yang diturunkan oleh Allah s.w.t dan yang dibawa oleh Rasulullah s.a.w. Dalam hal ini meringkaskan al-hikmah sebagai kekuatan intelektual.

Menafsirkan hikmah dalam empat bentuk iaitu; peringatan al-Quran 'مو اعظ القرأن'; kefahaman dan pengetahuan ; utusan 'النبوة', dan; rahsia keajaiban kandungan al-Quran. Walau bagaimanapun, mengkategorikan dua bentuk hikmah iaitu: utusan, dan; ilmu serta kesungguhan, petunjuk yang terang dalam meletakkan sesuatu pada tempatnya. Jika diperhatikan dengan teliti kedua-dua pandangan tersebut memperjelaskan lagi hikmah yang dimaksudkan membawa maksud ilmu dan kefahaman. Hal ini membawa erti sekiranya seseorang

\footnotetext{
15 Al-Razi, Muhammad ar Razi Fakhruddin, diau al din.

${ }^{16}$ Jawiah Dakir, Dasar Dan Kaedah Pembentukan Masyarakat Islam Menurut Perspektif Al-Sunnah.
} 
bertindak dengan hikmah maka ia telah bertindak dengan ilmu dan kebijaksanaan. Hikmah dalam Islam membawa pengertian kebaikan yang luas dalam memahami Islam secara menyeluruh merangkumi penegetahuan agama, akhlak dan tingkahlaku sebagai tanda syukur di atas nikmat dan kelebihan yang dikurniakanNya. Pernyataan ini adalah natijah daripada pemikiran, percakapan dan tingkah laku yang berdasarkan metod hikmah. ${ }^{17}$

Meletakkan tiga rukun yang menjadi syarat penting kepada metod hikmah ialah iaitu ilmu, toleransi dan ketabahan 'anat'. Umri memperincikan rukun yang menjadi sebab berlakunya hikmah kepada empat belas perkara iaitu, ikhlas dan takwa, taufik dan ilham, ilmu syariat, pengalaman dan kemahiran, petunjuk, ada matlamat, mahir dalam ilmu alam dan syariat, akal yang seimbang, adil; bukti, bersungguh-sungguh, doa dan istikharah, sabar, berperikemanusiaan serta berlemah lembut. Manakala untuk menjadikan hikmah sebagai cara atau metod dalam menangani permasalahan kehidupan, Qahtani meletakkan enam pendekatan iaitu strategi yang bijak 'al suluk al bakim', beramal dengan ilmu dan ikhlas, istiqamah, kemahiran dan pengalaman, diplomasi politik 'al siasah al hakimah', berkepakaran dalam dakwah kepada Allah. Jika diperhatikan dan diamati kesemua syarat tersebut berkaitan dengan ilmu. Maka sangat jelas hikmah itu mempunyai kaitan yang erat dengan ilmu dan kebijaksanaan.

Dalam melaksanakan hikmah sebagai manhaj kepada kelompok gelandangan dan berisiko perlunya kepada kata-kata yang berhikmah dan tindakan yang berhikmah. Kata-kata yang berhikmah terbahagi kepada tiga iaitu peringatan yang baik sama ada kata-kata yang memberi pelajaran dan kata-kata yang memberi pengajaran, galakan dan ugutan serta kata-kata perumpamaan atau kiasan kepada peristiwa. Metod ini dilihat sebagai alternatif yang menarik kerana lazimnya manusia amat suka kepada penceritaan kisah dan peristiwa.

Pengkajian metod untuk membentuk individu melalui agama berpandukan al-Quran dan al-hadith telah dirungkaikan oleh pengkaji-pengkaji Islam yang muktabar. Daripada kupasan-kupasan yang dibuat oleh sarjana Islam jelas menunjukkan bahawa Islam adalah sebagai cara hidup sebenarnya membawa manusia ke jalan yang lebih baik dan sejahtera. ${ }^{18}$ Agama menjadi sistem kepercayaan yang menyatukan individu dalam komuniti

\footnotetext{
${ }^{17}$ Mahjub, Abbas, Al Hikmah Wa Al Hiwar Calaqob Tubadiliyyah (Khartum: Calam al kutub al Hadis, 2004).

${ }^{18}$ Mahjub, Abbas.
} 
manakala ${ }^{19}$ menjadi satu tenaga sosial yang menyatukan penganutnya.Hal ini bertepatan dengan apa yang digariskan oleh al-sunnah yang mentarjihkan bahawa al-din itu sebagai satu nasihat.

Sabda Rasulullah s.a.w:

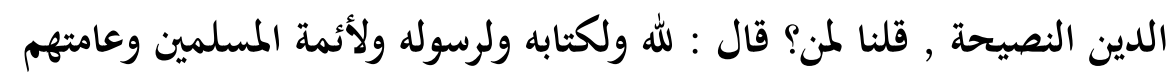

(Muslim t.th., al-Iman bab bayan 'anna al-din al-nasibah 1:74) Agama adalab nasibat pengajaran. Kami bertanya: bagi siapa? Jawab Rasulullah SAW: bagi Allah, kitabnya, RasuINya, imam-imam yang Islam dan sekalian orang Islam.

Nasihat bagi sekalian orang Islam ialah hendaklah diberi tunjuk ajar mengenai dunia dan akhirat mereka, mengajar apa yang mereka tidak tahu mengenai urusan agama, menolak kemudaratan daripada mereka, menyuruh mereka kepada yang makruf dan melarang yang mungkar dan sebagainya yang berhubungan dengan kemaslahatan orang Islam. Dengan penerangan ini, jelaslah bahawa agama itu sebagai nasihat dan pengajaran kepada orang Islam, tetapi dari sudut pembentukan masyarakat Islam, ia boleh dirujuk kepada nasihat dan pengajaran kepada sekalian manusia. ${ }^{20}$ Maka dapat difahami bahawa nasihat itu adalah sokongan kepada mereka untuk membina kekuatan diri dan hidup cara yang direstui oleh Allah. Seterusnya Allah s.w.t. berfirman dalam kitab-Nya tentang peringatan dan nasihat ini dalam Qs. al-Nisa: 63.

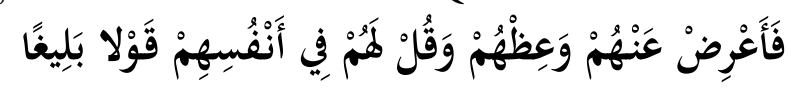

Dan berilah nasihat pengajaran kepada mereka dan katakanlah kepada mereka katakata yang boleh memberi kesan pada hati mereka.

Nasihat dan galakan adalah dua komponen yang mampu dijadikan sistem sokongan kepada individu. Hikmah dan nasihat merupakan metod untuk membentuk masyarakat Islam khususnya dan masyarakat lain amnya. ${ }^{21}$ Metod ini dilihat sesuai dan seiring dengan apa yang digariskan yang menyatakan bahawa al-Din itu adalah sebagai nasihat. Hikmah itu ditafsirkan sebagai apa-apa yang diturunkan ${ }^{22}$ sebagai hujah yang pasti yang membawa

\footnotetext{
${ }^{19}$ Jawiah Dakir, Dasar Dan Kaedah Pembentukan Masyarakat Islam Menurut Perspektif Al-Sunnah.

20 Ibid.

21 Ibid.

${ }^{22}$ Ibnu Kathir, Abu al-Fida' Ismail bin Kathir al-Quraishiyyi al-Damashqiyyi, Tafsir Al-Quran Al-Azim (Beirut: Alam al-Kutb, 1985).
} 
kepada akidah yang betul. ${ }^{23}$ Dengan erti kata lain hikmah itu merangkumi alQuran dan sunnah. ${ }^{24}$ Sehubungan dengan itu pembinaan sistem sokongan yang sangat signifikan adalan ad-din sebagai nasihat dan galakan. Kedua-dua item ini mampu membina daya tahan gelandangan.

Nasihat juga disebut sebagai al-mavizzah al-hasanah, menyebut almañah al-hasanah bermaksud nasihat atau pengajaran yang menarik dan dengan menyebut peristiwa-peristiwa yang berlaku dalam kehidupan manusia yang boleh dijadikan iktibar supaya manusia dapat mematuhi perintah Allah dan laranganNya. ${ }^{25}$ Hal ini sangat signifikan dengan pembentukan diri seseorang. Sekiranya nasihat yang bertepatan dengan ad-Din ini diaplikasikan dengan metod yang murni dan ikhlas, maka ia akan memberikan satu sistem sokongan yang berkesan kepada gelandangan.

Di samping nasihat yang baik, metod galakan adalah sangat sesuai bagi membina motivasi. ${ }^{26}$ Namun begitu galakan sahaja tidak mencukupi kerana momentum tidak dapat dilonjakkan kerana akan bersifat pasif. Kaedah altarghib (galakan) dan al-tarbib (ancaman) adalah sebagai salah satu cara yang penting dalam usaha menyeru manusia ke jalan Allah. Rasulullah s.a.w. menggunakan kaedah al-targhib dan al-tarbib dalam melaksanakan pembentukan masyarakat Islam. ${ }^{27}$ Dengan metod ini manusia dapat didedahkan kepada kebaikan dan keburukan yang akan diterima sebagai balasan sikap yang menerima atau menolak terhadap ajaran Allah s.w.t. Seperti mana dalam bab mentaati Rasul dan tidak mendustakannya, Abu Hurairah r.a meriwayatkan:

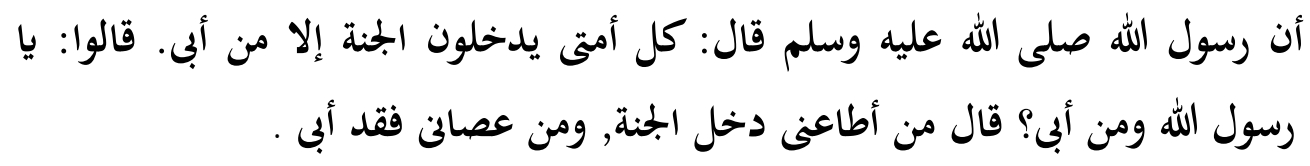

(al-Bukhari t.th., al-I'tisam bab al-iqtida' bisunan Rasulullah s.a.w. 9:114) Sesungguhnya Rasulullah s.a.w. bersabda: setiap umatku akan masuk syurga, kecuali orang yang enggan. Mereka (sahabat) berkata: Wahai Rasulullah, siapakah yang enggan? Rasulullah s.a.w. bersabda: siapa yang mentaatiku, ia masuk syurga dan sesiapa yang mengingkariku sesunggubnya ia enggan.

\footnotetext{
${ }^{23}$ Al-Razi, Muhammad ar Razi Fakhruddin, diau al din, Tafsir Al Fakhru Al Razi.

${ }^{24}$ Jawiah Dakir, Dasar Dan Kaedah Pembentukan Masyarakat Islam Menurut Perspektif Al-Sunnah.

${ }^{25}$ Ibnu Kathir, Abu al-Fida' Ismail bin Kathir al-Quraishiyyi al-Damashqiyyi, Tafsir Al-Quran Al-Azim.

${ }^{26}$ Muhammad al-Ghazali, Terj.Fiqh Sirah (Kuala Lumpur: Pustaka Salam, 2010).

${ }^{27}$ Jawiah Dakir, Dasar Dan Kaedah Pembentukan Masyarakat Islam Menurut Perspektif Al-Sunnah.
} 
Hadith di atas mengandungi unsur targhib dan tarbib yang selari. Ia sangat penting dalam komunikasi hari ini terutamanya untuk memberi galakan dan motivasi dan dalam masa yang sama tidak mudah hanyut dengan galakan tersebut maka digandingkan ia dengan unsur tarbib sebagai ancaman agar tidak lalai. Begitu Allah s.w.t. selalu memberikan janji baik kepada yang mentaatiNya dan janji buruk kepada yang ingkar kepadaNya (Qs. Nuh:10-12; Qs. al-A ${ }^{c}$ raf: 63; Qs. al-Taghabun: 9-10). Kesemua ayat tersebut mengandungi unsur targhib dan tarbib.

Allah s.w.t. memerintahkan Rasulullah s.a.w. supaya memberi pengajaran nasihat kepada orang-orang munafik tentang keburukan sifat buruk mereka, melalui perkataan yang memberi kesan di jiwa mereka bagi menegah keburukan mereka. Sekalipun ayat ini ditujukan kepada orang-orang munafik, namun kandungannya meliputi semua golongan manusia. ${ }^{28}$ Nasihat dan pengajaran ini bersifat holistik dan tentunya sesuai digunakan kepada setiap agama dan bangsa. Nasihat itu juga dilihat sebagai satu sokongan dan hubungan interpersonal untuk mencapai tahap kestabilan dalam emosi. Hal ini adalah kerana dalam nasihat itu dikatakan mempunyai sentuhan kemanusiaan. Individu juga dikatakan memerlukan sentuhan kemanusiaan (buman touch) sebagai pemangkin emosi yang positif dan identiti yang baik. Mereka yang melalui proses tersebut akan membentuk kemahiran sosial dan tingkah laku, pembentukan identiti, tingkah laku serta sosio-emosi. ${ }^{29}$

Menerusi kupasan al-hukmah dan al-Din al-nasihah ini maka dibawakan enam manhaj bimbingan sosial yang diperolehi hasil daripada penelitian dan penganalisaan menerusi pandangan sarjana. Kesemua manhaj tersebut adalah daripada al-Quran dan hadith sebagai alternatif menangani gelandangan dan kelompok individu berisiko.

1. Melazimi Istigfar

Metod ini merupakan perkara asas untuk mengembalikan ketenangan ruhiyyah. Allah s.w.t berfirman dalam surah ali-Imran dengan menyebut secara jelas tentang istighfar ini.

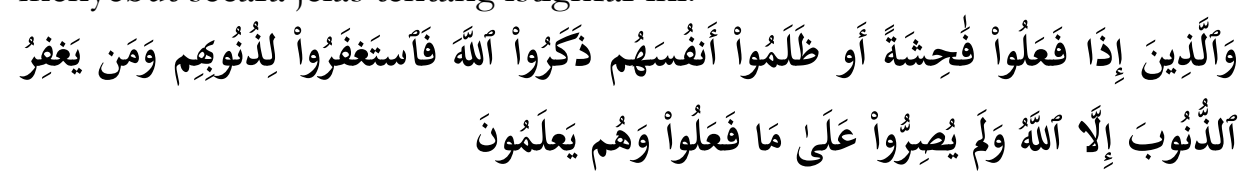

\footnotetext{
${ }^{28}$ Ibid.

${ }^{29}$ Mariani Mansor, "Faktor-Faktor Persekitaran Ekologikal Manusia Ke Atas Perkembangan Personaliti Dan Daya Tahan Kanak-Kanak Mangsa."
} 
Dan juga orang-orang yang apabila melakukan perbuatan keji atau menganiaya diri sendiri, mereka segera ingat kepada Allab lalu memohon ampun akan dosa mereka dan sememangnya tidak ada yang mengampunkan dosa-dosa melainkan Allah dan mereka juga tidak meneruskan perbuatan keji yang mereka telah lakukan itu, sedangkan mereka mengetahui (akan salabnya dan akibatnya).

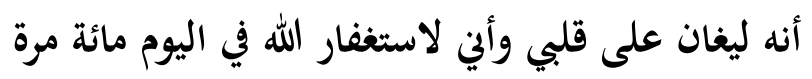

(Muslim fi sahihihi kitab al-Zikr wa al-Duca bab 12, 17:6797)

Sesunggubnya aku beristughfar (memohon ampun) serratus kali sehari.

Perlu difahamkan bahawa amalan istighfar tidak memerlukan pengkhususan tempat. Ia hanya perlu dilakukan secara santai dan dilazimi dengan lisan. Dalam kitabnya al-sakhsiyat al-Insan fi al-turath al-Islamiyy.pada pengamatan pengkaji ia lebih menjadikan istighfar sebagai satu kebiasaan kerana dengan istighfar hamba akan dekat dengan Allah, sebaliknya syaitan akan menghindarinya. ${ }^{30}$

2. Nasihat supaya memelihara solat

Firman Allah s.w.t dalam Qs. Hud: 114

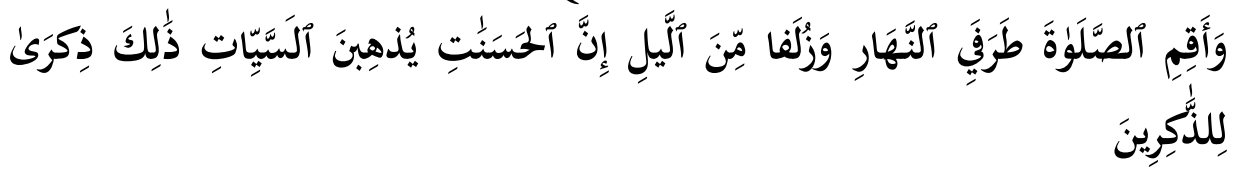

Dan dirikanlah sembabyang (wahai Muhammad, engkau dan umatmu), pada dua bahagian siang (pagi dan petang) dan pada waketu-waktu yang berhampiran dengannya dari waktu malam. Sesunggubnya amal-amal kebajikan (terutama sembahyang) itu menghapuskan kejahatan. Perintab-perintah Allah yang demikian adalab menjadi peringatan bagi orang-orang yang mahu beringat.

Firman Allah s.w.t dalam Qs. al-Ankabut: 45

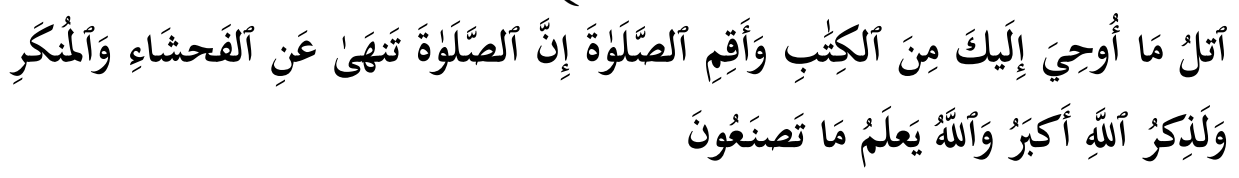

Bacalah serta ikutlah (wahai Muhammad) akan apa yang diwabyukan kepadamu dari Al-Quran dan dirikanlab sembabyang (dengan tekun); sesunggubnya sembabyang itu mencegah dari perbuatan yang keji dan mungkar dan sesunggubnya mengingati

${ }^{30}$ Asqalani, Ibnu Hajar, Fathul Baari: Penjelasan Kitab Shabih Al-Bukhari (Jakarta: Pustaka Azzam, 2006). 
Allah adalab lebih besar (faedahnya dan kesannya) dan (ingatlab) Allah mengetabui akan apa yang kamu kerjakan.

Sabda Nabi s.a.w:

\section{إنما الصلاة لقراءةالقرءان وذكر الله عز وجل فإذا كنت فيها فليكن ذلك شأنك}

(Abu Dawud t.th., al-Salah bab tashmit al-catis fi al-salah 1:245)

Sesunggubnya solat itu adalah bacaan al-Quran dan zikir Allah s.w.t. Apabila engkau di dalam sembanhyang hendaklah engkau tetap dalam keadaan engkau itu.

Solat adalah pencegah daripada perbuatan keji dan mungkar. Amalan hidup yang tidak berkualiti juga boleh dihapuskan dengan solat. Sekiranya solat mampu didirikan maka hubungan hamba dan Tuhan akan kukuh hidupnya dipandu. Hendaklah sesuatu amalan itu terutamanya solat dikerjakan sesempurna mungkin. Hal ini akn meninggalkan kesan yang mendalam kepada pelakunya. ${ }^{31}$

3. Menundukkan pandangan dan pelihara syahwat

Firman Allah s.w.t dalam Qs. al-Nur: 30

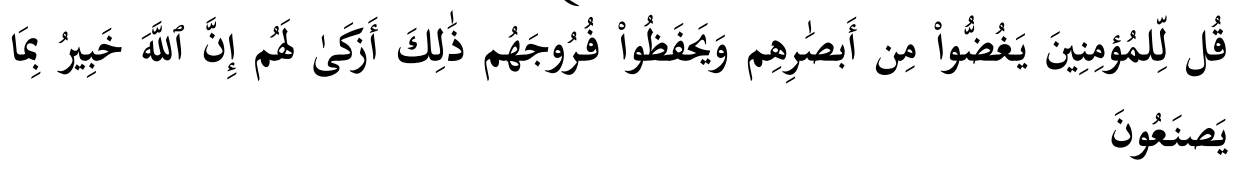

Katakanlah (wahai Mubammad) kepada orang-orang lelaki yang beriman supaya mereka menyekat pandangan mereka (daripada memandang yang haram) dan memelihara kehormatan mereka. Yang demikian itu lebih suci bagi mereka; sesunggubnya Allab Amat Mendalam PengetabuanNya tentang apa yang mereka kerjakan.

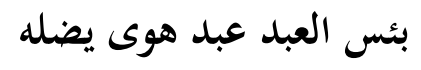

(al-Tirmidhi t.th., Abwab sifat al-Qiyamah bab 14,4:54)

Sejahat-jahat manusia ialah hamba yang disesatkan oleh hawa nafsunya.

Kedua-dua dalil di atas menunjukkan bahawa terdapat larangan yang berupa peringatan daripada Allah dan RasulNya agar menjauhkan diri daripada hawa nafsu yang kotor kerana ia merosakkan diri manusia. Ia akan

31 Ibid 
menjadikan manusia lemah atau pun sejahat-jahat manusia. Oleh itu ia akan membawa kerosakan yang disebabkan hawa nafsu. ${ }^{32}$

4. Tidak berputus asa

Firman Allah s.w.t dalam Qs. al-Zumar: 53

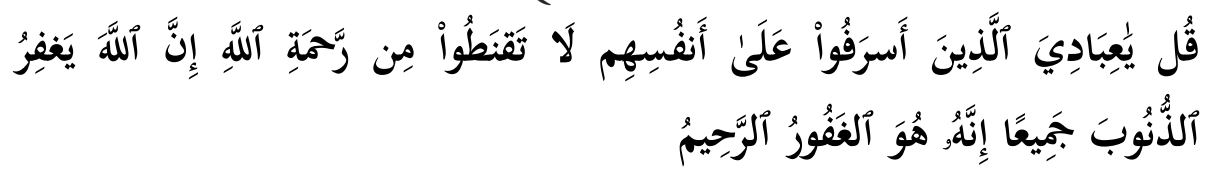

Katakanlah (wahai Muhammad): Wahai hamba-hambaKu yang telah melampani batas terhadap diri mereka sendiri (dengan perbuatan-perbuatan maksiat), janganlah kamu berputus asa dari rahmat Allah, kerana sesunggubnya Allah mengampunkan segala dosa; sesunggubnya Dialah jua Yang Maba Pengampun, lagi Maha Mengasibani.

$$
\text { إن الله لا ينظر إلى صوركم وأموالكم ولكن ينظر إلى قلوبكم وأعمالكم }
$$

(Muslim t.th., al-Bir wa al-silah wa al-adab bab tabrim sulm al-Muslim, 4:1987) Sesunggubnya Allah tidak melihat kepada rupa bentuk kamu dan harta kamu kamu, tetapi Dia melihat kepada hati kamu (iman kamu) dan amalan-amalan kamu.

Kupasan ayat al-Quran dan hadith yang telah disebutkan tadi menunjukkan bahawa sikap putus asa dalam mengharapkan rahmat Allah hendalah dijauhkan. Allah s.w.t juga memberi harapan kepada hambaNya agar sentiasa bersagka baik kepadaNya kerana Allah adalah seperti yang hambaNya sangkakan. Sikap tidak putus asa akan membuatkan setiap hamba sentiasa berusaha mendapat keredhaanNya.

5. Perbanyakkan sedekah

Firman Alah s.w.t dalam Qs. al-Nisa: 114.

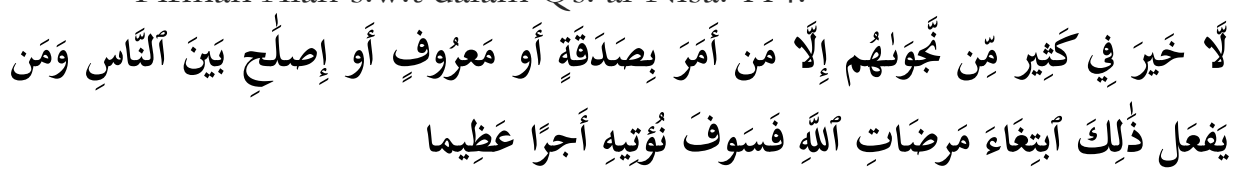

Tidak ada kebaikean pada kebanyakan bisik-bisikan mereka, kecuali (bisik-bisikan) orang yang menyurub bersedekah atau berbuat kebaikan atau mendamaikan di antara manusia dan sesiapa yang berbuat demikian dengan maksud mencari keredaan Allah, tentulah Kami akan memberi kepadanya pahala yang amat besar.

\footnotetext{
${ }^{32}$ Jawiah Dakir, Dasar Dan Kaedah Pembentukan Masyarakat Islam Menurut Perspektif Al-Sunnah.
} 


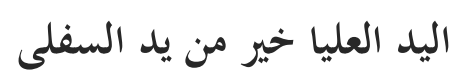

(al-Bukhari t.th., al-Zakat bab la sadaqah illa 'an zahr ghaniyy 2:139)

Tangan yang memberi lebih baik daripada tanhan yang menerima.

Kefahaman tentang sedekah adalah sangat perlu. Hal ini kerana ramai beranggapan bahawa setiap sedekah mesti memerlukan kepada wang ringgit. Namun sedekah yang paling ringan da mudah dilakukan adalah senyum dan kata-kata yang baik. Syarak juga menggalakkan sedekah kerana dengannya harta dapat dinikmati bersama antara yang miskin dan yang kaya. Namun jika tidak mampu untuk menyedekahkan harta dan wang ia memadai dengan kerja amal dan ta ${ }^{c}$ awun (tolong-menolong). Hal ini termasuk dalam perkara yang akan mendapat naungan pada hari kiamat kelak. Ia merupakan satu motivasi kepada golongan gelandangan untuk melihat konsep sedekah dengan skop yang lebih luas dan mampu dilaksanakan.

6. Taubat dan doa

Firman Allah s.w.t dalam Qs. al-Furqan: 70
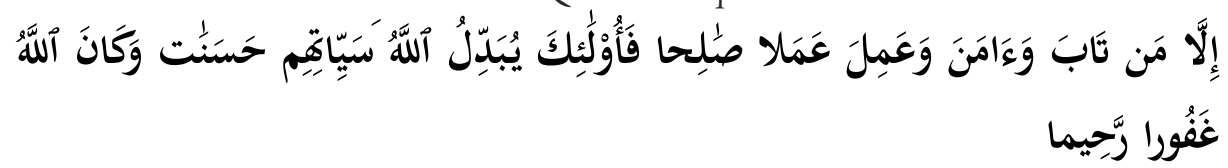

Kecuali orang yang bertaubat dan beriman serta mengerjakan amal yang baik, maka orang-orang itu, Allah akan menggantikan (pada tempat) kejahatan mereka dengan kebaikan dan adalah Allah Maha Pengampun, lagi Maha Mengasibani.

Firman Allah s.w.t dalam Qs. al-Tahrim: 8

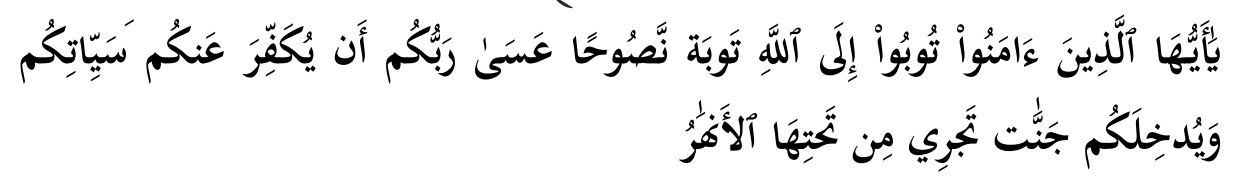

Wahai orang-orang yang beriman. Bertaubatlah kamu kepada Allah dengan Taubat Nasuba, mudah-mudahan Tuhan kamu akan menghapuskan kesalaban-kesalahan kamu dan memasukkan kamu ke dalam Syurga yang mengalir di bawahnya beberapa sungai. 


\section{لو أخطأتم حتى تبلغ خطاياكم السماء ثم الإستغفار بعد الذنب}

(Ibnu Majah fi sunanihi, kitab al-Zubd bab ke 30, 4:2252)

Jika kamu melakukan kesilapan sehingga dosamu mencapai langit, kemudian beristighfar maka diampunkan dosa tersebut.

Setiap hamba adalah pendosa yang memerlukan taubat atas dosanya. Hal ini kerana manusia tidak pernah sunyi daripada salah dan lupa. Manusia akan cenderung silap dan lupa. Ketika itulah dosa akan dilakukan sama ada sengaja atau tidak. Oleh itu mohon ampun dengan jalan taubat dan doa akan membuatkan manusia kembali merasakan diri hamba serta mendatangkan keinsafan. Menerusi kesemua perbincangan yang terhasil dalam penulisan ini maka enam manhaj ini diteliti mempunyai kepentingan dan dalil yang sungguh kuat untuk diadaptasikan ke atas golongan gelandangan dan kelompok individu yang berisiko. Manhaj yang berteraskan al-Quran dan hadith sepenuhnya ini adalah yang terbaik untuk hamba daripada Khaliq. Dapat diperhatikan keenamenam manhaj ini menggunakan pendekatan yang lunak dan sangat sesuai dengan tema al-Hikmah dan al-Din al-nasibah.

\section{Simpulan}

Menerusi kupasan yang telah dibincangkan dalam analisis tinjauan literatur, ia telah menjawab persoalan kajian dan telah mencapai objektif kajian dalam penulisan ini. Perbincangan yang dimulakan dengan definisi kepada pemboleh ubah atau tema al-Hikmah dan al-Din al-Nasibah. Ia kemudiannya diikuti dengan metod atau manhaj al-bikmah dan al-Din al-Nasibah sebagai alternatif menangani gelandangan dan kelompok individu berisiko berteraskan al-Quran dan hadith. Sebanyak enam manhaj bimbingan sosial telah dirungkaikan untuk diadaptasikan ke atas golongan gelandangan dan kelompok individu berisiko. Keenam-enam manhaj tersebut ialah melazimi istighfar, nasihat memelihara solat, menundukkan pandangan dan syahwat, tidak berputus asa, perbanyakkan sedekah serta taubat dan doa. Kesemua manhaj ini dilihat mampu diserap dalam aktiviti mereka walaupun secara santai kerana fitrah manusia pasti akan tenang apabila dihubungkan terus dengan khaliq atau penciptanya. 


\section{Daftar Pustaka}

al-Asqalani, Ibnu Hajar. Fathul Baari: Penjelasan Kitab Shabih Al-Bukhari. Jakarta: Pustaka Azzam, 2006.

Cohen, S., Mermelstein, R., Kamarck, T. \& Hoberman, H. M. Measuring the Functional Components of Social Support. Dlm. I. G. Sarason \& B. R. Sarason (Pnyt.). Social Support: Theory, Research and Application. Martinus Nijhoff Boston, 1985.

Dakir, Jawiah. Dasar Dan Kaedah Pembentukan Masyarakat Islam Menurut Perspektif Al-Sunnah. Selangor: International Law Book Services., 2008.

Faridah, Nor. Identiti Muslim Menurut Pandangan Tariq Ramadhan. Kuala Lumpur: Institut Terjemahan dan Buku Malaysia Berhad., 2015.

al-Ghazali, Muhammad. Terj.Figh Sirah. Kuala Lumpur: Pustaka Salam, 2010. al-Habshi, Sharifah Mariam. "Homelessness in Kuala Lumpur Malaysia: A Case of Agenda Denial." International Journal Of Social Science Tomorrow 1 (2012): 2 .

Ibn Khaldun, Abd al-Rahman bin Muhammad Khaldun al-Hadrami. Mukaddimah Ibn Khaldun. Terj. Dewan Bahasa Dan Pustaka. Kuala Lumpur: Dewan Bahasa dan Pustaka, 2002.

Ibnu Kathir, Abu al-Fida' Ismail bin Kathir al-Quraishiyyi al-Damashqiyyi. Tafsir Al-Quran Al-Azim. Beirut: Alam al-Kutb, 1985.

Langgulung, Hassan. Asas-Asas Pendidikan Islam. Kuala Lumpur: Dewan Bahasa dan Pustaka, 1987.

Mahjub, Abbas. Al Hikmah Wa Al Hiwar Calaqob Tubadiliyyah. Khartum: Calam al kutub al Hadis, 2004.

Mansor, Mariani. "Faktor-Faktor Persekitaran Ekologikal Manusia Ke Atas Perkembangan Personaliti Dan Daya Tahan Kanak-Kanak Mangsa." Universiti Kebangsaan Malaysia, 2004.

Mohamed, Rafiza. Gelandangan Antara Tret Personaliti Dan Religiositi. Pertama. Kuala Lumpur: Institut Terjemahan dan Buku Malaysia Berhad., 2015.

Munawar, Ahmad \& Mohd Nor Shahizan. Memahami Kuantitatif \& Kualitatif Dalam Penyelidikan Pengajian Islam. Bangi: FPI Universiti Kebangsaan Malaysia., 2012.

Al-Razi, Muhammad Fakhruddin. Tafsir Al Fakhru Al Razi. Beirut: Dar al Fikr, 2005.

Yap, Wong Kin, Lee Chew Chang, Mohd saiful Azri Mohd Fouzi, Muhamat Hamzah Eksan, Muhd Farid Ashman Abd Latif. Masalah Gelandangan 
Kuala Lumpur: Satu Tinjauan (Pengantar Dasar Sosial). Kuala Lumpur: Universiti Malaya, 2014. 